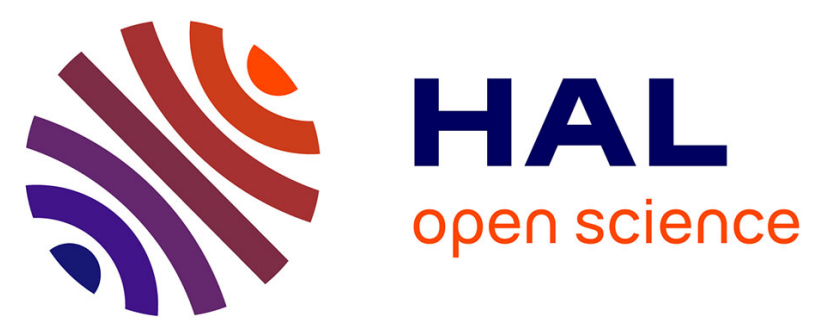

\title{
Quantitative assessment of sodium mass removal using ionic dialysance and sodium gradient as a proxy tool: comparison of high-flux hemodialysis versus online hemodiafiltration
}

Annie Rodriguez, Marion Morena, Anne-Sophie Bargnoux, Leila Chenine, Hélène Leray-moragues, Jean-Paul Cristol, Bernard Canaud

\section{To cite this version:}

Annie Rodriguez, Marion Morena, Anne-Sophie Bargnoux, Leila Chenine, Hélène Leray-moragues, et al. Quantitative assessment of sodium mass removal using ionic dialysance and sodium gradient as a proxy tool: comparison of high-flux hemodialysis versus online hemodiafiltration. Artificial Organs, In press, 10.1111/aor.13923 . hal-03125396

\author{
HAL Id: hal-03125396 \\ https://hal.science/hal-03125396
}

Submitted on 16 Jun 2021

HAL is a multi-disciplinary open access archive for the deposit and dissemination of scientific research documents, whether they are published or not. The documents may come from teaching and research institutions in France or abroad, or from public or private research centers.
L'archive ouverte pluridisciplinaire HAL, est destinée au dépôt et à la diffusion de documents scientifiques de niveau recherche, publiés ou non, émanant des établissements d'enseignement et de recherche français ou étrangers, des laboratoires publics ou privés. 


\title{
Quantitative assessment of sodium mass removal using ionic dialysance and sodium gradient as a proxy tool: Comparison of high-flux hemodialysis versus online hemodiafiltration
}

\author{
Annie Rodriguez $^{1}$ | Marion Morena ${ }^{2}$ | Anne-Sophie Bargnoux ${ }^{2}$ | Leila Chenine ${ }^{3}$ | \\ Hélène Leray-Moragues $^{1}$ | Jean Paul Cristol ${ }^{2}$ | Bernard Canaud $^{4,5}$
}

${ }^{1}$ AIDER Santé, Montpellier, France

${ }^{2}$ Biochemistry/Hormonology Department, PhyMedExp, University of Montpellier, INSERM, CNRS, University Hospital Center of Montpellier, Montpellier, France

${ }^{3}$ Nephrology Department, University

Hospital Center of Montpellier,

Montpellier, France

${ }^{4}$ Nephrology, University of Montpellier, Montpellier, France

${ }^{5}$ Global Medical Office, FMC Deutschland, Bad Homburg, Germany

\section{Correspondence}

Bernard Canaud, Centre for Medical Excellence, FMC Deutschland GmbH, Else Kröner Strasse 1, Bad Homburg 61352, Germany.

Email: bernard.canaud@fmc-ag.com

\begin{abstract}
Restoration and maintenance of sodium are still a matter of concern and remains of critical importance to improve the outcomes in homeostasis of stage 5 chronic kidney disease patients on dialysis. Sodium mass balance and fluid volume control rely on the "dry weight" probing approach consisting mainly of adjusting the ultrafiltration volume and diet restrictions to patient needs. An additional component of sodium and fluid management relies on adjusting the dialysate-plasma sodium concentration gradient. Hypotonicity of ultrafiltrate in online hemodiafiltration (ol-HDF) might represent an additional risk factor in regard to sodium mass balance. A continuous blood-side approach for quantifying sodium mass balance in hemodialysis and ol-HDF using an online ionic dialysance sensor device ("Flux" method) embedded on hemodialysis machine was explored and compared to conventional cross-sectional "Inventory" methods using anthropometric measurement (Watson), multifrequency bioimpedance analysis (MF-BIA), or online clearance monitoring (OCM) to assess the total body water. An additional dialysate-side approach, consisting of the estimation of inlet/outlet sodium mass balance in the dialysate circuit was also performed. Ten stable hemodialysis patients were included in an "ABAB"-designed study comparing high-flux hemodialysis (hf-HD) and ol-HDF. Results are expressed using a patient-centered sign convention as follows: accumulation into the patient leads to a positive balance while recovery in the external environment (dialysate, machine) leads to a negative balance. In the blood-side approach, a slight difference in sodium mass transfer was observed between models with hf-HD (-222.6 [-585.1-61.3], -256.4 [-607.8-43.7], -258.9 [-609.8-41.3], and -258.5 [-607.8-43.5] mmol/session with Flux and Inventory models using $\mathrm{V}_{\text {Watson }}, \mathrm{V}_{\mathrm{MF}-\mathrm{BIA}}$, and $\mathrm{V}_{\mathrm{OCM}}$ values for the volumes of total body water, respectively; global $P$ value $<.0001)$ and ol-HDF modalities (-235.3 [-707.4-128.3], -264.9 [-595.5-50.8], -267.4 [-598.1-44.1], and -266.0 [-595.6-55.6] mmol/session with Flux and Inventory models using $\mathrm{V}_{\text {Watson, }}$, $\mathrm{V}_{\mathrm{MF}-\mathrm{BIA}}$, and $\mathrm{V}_{\text {OCM }}$ values for the volumes of total body water, respectively; global $P$ value $<.0001)$. Cumulative net ionic mass balance on a weekly basis remained virtually similar in hf-HD and ol-HDF using Flux method $(P=$ n.s. $)$. Finally, the
\end{abstract}


comparative quantification of sodium mass balance using blood-side (Ionic Flux) and dialysate-side approaches reported clinically acceptable (a) agreement (with limits of agreement with $95 \%$ confidence intervals (CI): -166.2 to 207.2 ) and (b) correlation (Spearman's rho $=0.806 ; P<.0001$ ). We validated a new method to quantify sodium mass balance based on ionic mass balance in dialysis patients using embedded ionic dialysance sensor combined with dialysate/plasma sodium concentrations. This method is accurate enough to support caregivers in managing sodium mass balance in dialysis patients. It offers a bridging solution to automated sodium proprietary balancing module of hemodialysis machine in the future.

\section{K E Y W O R D S}

dialysis, cardiovascular outcome, fluid management, sodium homeostasis, sodium modeling, chronic kidney disease

\section{1 | INTRODUCTION}

Sodium mass balance and sodium homeostasis restoration are of critical importance in stage 5 chronic kidney disease patients on maintenance dialysis (CKD-5D) to improve the cardiovascular and global outcomes in this high-risk population. ${ }^{1-3}$ Restoring sodium and fluid homeostasis in CKD-5D patients while preventing hypertension and chronic fluid overload is a permanent quest for almost 50 years to prevent morbidity (ie, hospitalization) and to reduce the occurrence of cardiovascular events. ${ }^{4}$

Sodium mass balance and fluid volume control in CKD-5D patients rely on the "dry weight" probing approach that consists in correcting extracellular fluid excess mainly by means of ultrafiltration (ie, weight loss) and in reducing interdialytic fluid volume intake (ie, weight gain) by sodium and fluid dietary restriction. ${ }^{5,6}$ Fluid volume control is easier achieved in patients keeping residual kidney function and/ or those following dietary recommendations. Weight loss is currently used as a surrogate of extracellular fluid volume and sodium mass removal (ie, $9 \mathrm{~g}$ of $\mathrm{NaCl}$ per liter of ultrafiltrate). However, this basic clinical approach is not sufficient if not considering sodium mass transfer resulting from the dialysate-plasma sodium concentration gradient which may affect positively or negatively the net sodium mass transfer. ${ }^{7,8}$ Considering these pitfalls and their long-term-associated risks, a more precise and reliable method to quantify sodium mass balance using ionic mass balance and sodium gradient as a proxy would be highly appealing in this difficult clinical setting. ${ }^{9-11}$

Online hemodiafiltration (ol-HDF) may represent an additional risk factor in regard to sodium mass balance as recently pointed out in a controversial issue. ${ }^{12,13}$ Sodium mass imbalance in ol-HDF may result from the combination of Donnan effect and protein concentration polarization effect onto the filter membrane resulting in a reduction of the effective sodium sieving coefficient by about $3 \%-5 \% .{ }^{14,15}$ In brief, sodium concentration in the ultrafiltrate is lower than in the substitution fluid leading to a relatively positive instantaneous sodium flux imbalance if one adopts a patient-centered approach. This phenomenon obviously amplified with larger exchange volumes might alter over time the net sodium mass balance of dialysis patients. Interestingly, two recent studies have addressed this concern specifically associated with online HDF: the first study has explored this question by quantifying and comparing the sodium mass removal in high-flux HD and online HDF using a basic Inventory method ${ }^{16}$; the second study has explored its clinical consequences by assessing fluid volume and hemodynamic status of HD- and HDF-treated patients in a large retrospective cohort study. ${ }^{17}$ In brief, both studies were reassuring since they did not find any significant differences in fluid volume status and sodium mass balance among the two dialysis modalities. Unfortunately, these studies did not provide a precise or direct sodium mass balance assessment.

The aim of this study was to explore further this important concern in order to improve dialysis patient care and to reduce potential risks associated with sodium imbalance in online HDF. The study had three aims: first to develop a more precise approach for quantifying sodium mass balance in hfHD and ol-HDF derived from ionic mass balance using the ionic dialysance sensor device and sodium gradient (Flux method) embedded on the hemodialysis machine; second to compare its findings to Inventory methods; third to compare sodium mass balance achieved in high-flux hemodialysis (hfHD) and high-volume online hemodiafiltration (ol-HDF).

\section{MATERIALS AND METHODS}

\section{$2.1 \quad$ Study design}

This study consisted of four phases (A-B-A-B design) lasting one month each which alternated use of high-volume online 
HDF and high-flux HD. The study adhered to the World Medical Association Declaration of Helsinki by insuring best clinical practice and patient safety and was approved by our local review board committee. After informed consent was obtained, 10 stable CKD-5D patients were included in the study and 120 dialysis sessions (60 hf-HD and 60 ol-HDF) were analyzed. Blood samples were collected in agreement with the biological collection declared at the Health French ministry under the following number DC-2008-417.

All patients received high volume online HDF at baseline based on three weekly dialysis sessions lasting 3-4 hours. Prescription parameters were kept constant and fitting patient needs and/or tolerance over the study period. Treatment time, blood and dialysate flow, ultrafiltration rate, and use of highflux dialyzer and anticoagulation were kept similar over the 4 months. Electrolyte prescription including dialysate sodium, potassium, calcium, magnesium, and buffer was kept constant and responding to patient needs. Dry weight, fluid volume, and hemodynamic management were not modified and left to the discretion of the referring physician. Over this 4-month follow-up period, the same hemodialysis machine was used (Fresenius 5008S HDF, Fresenius Medical Care, Bad Homburg, Germany) and the only change that occurred was linked to the dialysis modality choice, as such HDF option was activated or not on the dialysis machine. Ultrapurity of dialysis fluid was the same in the different study phases.

The study was performed over the first week of the month through the three sessions of the week based on regular monthly treatment adequacy assessment protocol. Monthly dialysis adequacy check-up consisted of withdrawing pre-dialysis and postdialysis blood samples during the mid-week dialysis session for lab test analyses and patient clinical assessment. Clinical assessment consisted mainly of blood pressure and hemodynamic assessments, but also fluid status assessment relying on a multifrequency bioimpedance analysis. In addition to blood sampling and laboratory tests, information relating to hemodialysis machines and patient electronic medical record was captured. Dialysis machines provided (a) standard information related to performances including blood, dialysate, substitution, and ultrafiltration flow and (b) additional measured parameters such as cumulative ionic dialysance, dialysate conductivity, plasma sodium estimate, total substitution, and ultrafiltration volume.

\section{2 | Patient characteristics}

Ten stable stage 5 chronic kidney disease patients (CKD-5D) on maintenance dialysis were enrolled in this study. There were nine males and one female with a median age of 76.3 years [57.6-84.4]. Four of them had diabetes mellitus and nine had significant comorbid conditions.

All patients received renal replacement therapy on a three per week basis schedule with sessions lasting 3-4 hours for at least 6 months. They were clinically stable at the time of enrollment. Online HDF was standard of care at baseline.

\subsection{Dialysis prescription}

Treatment time, blood flow, dialysate flow, electrolyte prescription, dry weight and ultrafiltration volume, substitution volume, and anticoagulation were adjusted to patient needs and treatment tolerance. All patients were treated with a highflux hemodialyzer and ultrapure dialysis fluid on a Fresenius 5008S hemodialysis machine (Fresenius Medical Care).

All patients were treated in center dialysis facility under the supervision of their usual medical staff and caregivers. Clinical monitoring was performed under local practice rules that consisted of a medical visit at each dialysis session and a monthly clinical, biological, and dialysis performance checkup that included a body composition monitoring by multifrequency bioimpedance (MF-BIA) measurement using the Body Composition Monitor (BCM) apparatus (Fresenius Medical Care). Information captured by dialysis machine, caregivers, blood lab tests, and MF-BIA was collected on a permanent basis and stored in the patient's electronic medical record.

\section{4 | Laboratory parameters}

Blood samples were collected as part of regular CKD-5D patient follow-up during the mid-week session before and after dialysis from the arterial line.

Routine laboratory analyses included plasma urea, creatinine, $\mathrm{Na}^{+}$, and serum albumin.

Plasma urea and creatinine were measured by isotope dilution mass spectrometry (ID-MS) traceable enzymatic method (Cobas 8000, Roche Diagnostics, Meylan, France). Serum albumin was determined by immunoturbidimetry (Cobas 8000 , Roche Diagnostics).

Plasma $\mathrm{Na}^{+}$concentration was determined using indirect potentiometry (Cobas 8000 , Roche Diagnostics with an analytical coefficient of variation of $0.74 \%$ ). Dialysate $\mathrm{Na}^{+}$concentration was measured using direct potentiometry (Omni S, Roche Diagnostics; with an analytical coefficient of variation of $0.93 \%$ ).

Plasma and dialysate $\mathrm{Na}^{+}$concentrations were also estimated using conductivity measurements by dialysis machine. Only estimated values of $\mathrm{Na}^{+}$were taken into account in calculations. Of note, the ionic dialysance sensor device relies on a proprietary algorithm that accounts for the Donnan effect and protein void volume as previously validated both in plasma and dialysate. ${ }^{18-22}$ Concordance with laboratory measurements has been controlled in the first part of this study. 


\section{5 | Calculations}

\subsection{1 | Dialysis dose delivered for urea}

Dialysis dose delivered for urea was calculated using single pool $(\mathrm{Kt} / \mathrm{V})_{\mathrm{sp}}{ }^{23}$ and equilibrated $(\mathrm{Kt} / \mathrm{V})_{\mathrm{eq}}{ }^{24}$ according to following Daugirdas formulas:

$$
\begin{aligned}
(\mathrm{Kt} / \mathrm{V})_{\mathrm{sp}}= & -\mathrm{Ln}\left(\mathrm{C}_{\text {urea_post }} / \mathrm{C}_{\text {urea_pre }}\right)-0.008 \times t_{d} \\
& +\left(\left(4-3.5 \times \mathrm{C}_{\text {urea_post }} / \mathrm{C}_{\text {urea_pre }}\right) \times\left(\mathrm{W}_{\text {pre }}-\mathrm{W}_{\text {post }}\right) / \mathrm{W}_{\text {post }}\right)
\end{aligned}
$$

$$
(\mathrm{Kt} / \mathrm{V})_{\mathrm{eq}}=(\mathrm{Kt} / \mathrm{V})_{\mathrm{sp}}-\left(0.6 \times(\mathrm{Kt} / \mathrm{V})_{\mathrm{sp}} / t_{d}\right)+0.03
$$

where $\mathrm{sp}$ is single pool, pre-correspond and post-correspond to pre-treatment and post-treatment conditions, respectively, $t_{d}$ is time on dialysis in hours, $\mathrm{C}_{\text {urea }}$ is urea concentration in $\mathrm{mmol} / \mathrm{L}$, and $\mathrm{W}$ is body weight in $\mathrm{kg}$.

\subsection{2 | Total body water}

Total body water was estimated from different formulas including (a) Watson anthropometric determination using post-dialysis body weight, ${ }^{25}$ (b) multifrequency bioimpedance analysis (MF-BIA) using BCM apparatus in pre-dialysis period, ${ }^{26}$ and finally (c) using indirect determination by calculating the $\left(\mathrm{K}_{\mathrm{OCM}} \mathrm{t}\right) /(\mathrm{Kt} / \mathrm{V})_{\text {eq_Daug }}$ ratio where $\left(\mathrm{K}_{\mathrm{OCM}} \mathrm{t}\right)$ represents the dialysis dose delivered to the patient and calculated from ionic dialysance using Online Clearance Monitoring (OCM) module from the 5008 machine (Fresenius Medical Care) and where (Kt/V) $)_{\text {eq_Daug }}$ represents the value of equilibrated Kt/V from Daugirdas equation calculated during the session. ${ }^{24}$

\subsubsection{Ionic mass balance as proxy of sodium mass balance (blood-side approach)}

Ionic mass balance was calculated from two different approaches: the first approach, namely "Ionic Flux Approach" consisted of using ionic dialysance and plasma sodium concentrations as estimated by the dialysis machine; the second approach, namely "sodium inventory approach" consisted of estimating sodium pool changes between the pre-dialysis and post-dialysis period.

Results of this study were expressed by adopting a patientcentered point of view, where accumulation into the patient leads to a positive sodium mass balance and recovery in the external environment (dialysate, machine) leads to a negative sodium mass balance.

\section{Sodium Ionic Flux approach}

To calculate sodium mass removal, we assumed that sodium mass transfer results from two components: the first component relies on the diffusive component that can be estimated from the product of sodium dialysance and dialysate plasma sodium concentration gradient; the second component relies on the convective component and can be estimated from the total ultrafiltration volume or patient weight loss. Dialysate conductivity $(\Gamma)$ was used as a surrogate of sodium concentration using the correlation established by Locatelli et al ${ }^{18}$ in which

$$
\mathrm{C}_{\mathrm{D} \_\mathrm{Na}+}=\Gamma \times 9.46+6.5
$$

where $\mathrm{C}_{\mathrm{D} \_\mathrm{Na}+}$ stands for dialysate sodium concentration and $\Gamma$ for dialysate conductivity

Diffusive sodium flux component. Mean ionic dialysance measured by the dialysance machine $\left(\mathrm{K}_{\mathrm{OCM}}\right)$ was used as a surrogate of sodium dialysance.

Logarithmic mean of plasma sodium $\left(\mathrm{C}_{\mathrm{B} \_\mathrm{Na}}\right)$ concentration was calculated from pre-dialysis $\left(\mathrm{C}_{\mathrm{B}_{-} \mathrm{Na}+}\right.$ pre $)$ and post-dialysis $\left(\mathrm{C}_{\mathrm{B}_{-} \mathrm{Na}+\text { _post }}\right)$ plasma sodium concentrations measured by the dialysis monitor as follows:

$\mathrm{c}_{\mathrm{B} \_\mathrm{Na}+}=\left(\mathrm{C}_{\mathrm{B} \_\mathrm{Na}+\_ \text {pre }}-\mathrm{C}_{\mathrm{B} \_\mathrm{Na}+\_ \text {post }}\right) / \mathrm{Ln}\left(\mathrm{C}_{\mathrm{B} \_\mathrm{Na}+\_ \text {pre }} / \mathrm{C}_{\mathrm{B} \_\mathrm{Na}+\text { _post }}\right)$

Dialysate sodium concentration $\left(\mathrm{C}_{\mathrm{D} \_\mathrm{Na}+}\right)$ was estimated from the conductivity cell of dialysis machine. All these measures are reliable as shown by previous studies and may be used for such calculation. Treatment time $\left(t_{d}\right)$ as measured by dialysis machine was used to calculate the cumulative diffusive sodium mass (M) transfer. This is expressed in the following formula:

$$
\mathrm{M}_{\mathrm{B} \_\mathrm{Na}+\text { dif }}=\mathrm{K}_{\mathrm{OCM}} \times\left(\mathrm{C}_{\mathrm{D} \_\mathrm{Na}+}-\mathrm{C}_{\mathrm{B} \_\mathrm{Na}+}\right) \times t_{d}
$$

Convective sodium flux component. Mean ultrafiltration rate $\left(\mathrm{Q}_{\mathrm{F}}\right)$, defined as the effective weight loss $\left(\mathrm{W}_{\mathrm{L}}\right)$ divided by the treatment time $\left(t_{d}\right)$, was used to calculate convective sodium flux.

Treatment time $\left(t_{d}\right)$ measured by dialysis machine was used to calculate the cumulative convective sodium mass transfer. This is expressed in the following formula:

$$
\mathrm{M}_{\mathrm{B} \_\mathrm{Na}+\text { conv }}=-\mathrm{Q}_{\mathrm{F}} \times \mathrm{C}_{\mathrm{B} \_\mathrm{Na}+} \times t_{d}
$$

Total sodium mass removed is then the sum of diffusive and convective components.

$$
\mathrm{M}_{\mathrm{B} \_ \text {Flux }}=\mathrm{M}_{\mathrm{B} \_\mathrm{Na}+\_ \text {dif }}+\mathrm{M}_{\mathrm{B} \_\mathrm{Na}+\_ \text {conv }}
$$




\section{Sodium inventory approach}

Sodium mass balance reflects the change in total sodium pool occurring between the beginning and end of the dialysis session. While osmotic distribution volume for sodium is total body water, the physical distribution volume for sodium is extracellular water. Therefore, initial sodium pool may be estimated as the product of pre-dialysis plasma sodium concentration $\left(\mathrm{C}_{\mathrm{B} \_\mathrm{Na}+\text { _pre }}\right)$ divided by 0.93 (to correct for plasma water concentration) times extracellular water $\left(\mathrm{V}_{\mathrm{ECW}}\right)$ plus weight loss $\left(\mathrm{W}_{\mathrm{L}}\right)$ while final sodium pool may be estimated as the product of post-dialysis plasma sodium concentration $\left(\mathrm{C}_{\mathrm{B} \_\mathrm{Na}+\text { _post }}\right)$ divided by 0.93 times extracellular water $\left(\mathrm{V}_{\mathrm{ECW}}\right)$. Inventory sodium mass balance is now the difference between the final and the initial patient sodium pool.

This may be summarized by the following equation:

$$
\mathrm{M}_{\text {Inv }}=\left(\mathrm{C}_{\mathrm{B} \_ \text {Na+_post }} / 0.93\right) \times \mathrm{V}_{\mathrm{ECW}}-\left(\mathrm{C}_{\mathrm{B}_{\text {NNa+_pre }}} / 0.93\right) \times\left(\mathrm{V}_{\mathrm{ECW}}+\mathrm{W}_{\mathrm{L}}\right)
$$

$\mathrm{M}_{\mathrm{Inv}}=\left[\mathrm{V}_{\mathrm{ECW}} \times\left(\mathrm{C}_{\mathrm{B} \_ \text {Na+_post }}-\mathrm{C}_{\mathrm{B} \_\mathrm{Na}+\text { _pre }}\right)-\mathrm{W}_{\mathrm{L}} \times \mathrm{C}_{\mathrm{B} \_ \text {Na+_pre }}\right] / 0.93$

To further explore the impact of extracellular water values on this calculation, we used different sources of total body water volumes, Watson anthropometric determination, MFBIA measurement in pre-dialysis period, and urea and ionic kinetic (OCM) from which we estimated extracellular fluid volume as one third of the total body water. Volumes of extracellular water were, respectively, named $\mathrm{V}_{\text {Watson }}, \mathrm{V}_{\text {MF-BIA }}$, and $\mathrm{V}_{\mathrm{OCM}}$.

\subsection{4 | Sodium mass balance (dialysate-side approach)}

Sodium mass balance using the dialysate-side approach consisted in estimating sodium instantaneous flux difference from dialysate outlet $\left(\mathrm{Q}_{\mathrm{D} \_ \text {out }} \times \mathrm{C}_{\mathrm{D}_{\text {_out_Na+ }}}\right)$ and inlet $\left(\mathrm{Q}_{\mathrm{D} \_ \text {in }}\right.$ $\left.\times \mathrm{C}_{\mathrm{D} \_ \text {in_Na+ }}\right)$ flow times treatment time $\left(t_{d}\right)$. Dialysate flows were assessed and collected from dialysis machine. As for the blood-side approach, results were expressed by adopting a patient-centered approach, where accumulation into the patient leads to a positive sodium mass balance and recovery in the external environment (dialysate, machine) leads to a negative sodium mass balance.

Instantaneous sodium mass balance (dialysate-side approach)

$\mathrm{M}_{\mathrm{D} \_ \text {inst }}=\mathrm{Q}_{\mathrm{D} \_ \text {in }} \times \mathrm{C}_{\mathrm{D} \_ \text {in_Na+ }}-\mathrm{Q}_{\text {D_out }} \times \mathrm{C}_{\text {D_out_Na+ }}$
Sodium mass balance (dialysate-side approach)

$$
\mathrm{M}_{\mathrm{D}}=\mathrm{M}_{\mathrm{D} \_ \text {inst }} \times t_{d}
$$

with $\mathrm{Q}_{\mathrm{D} \_ \text {in }}$ and $\mathrm{Q}_{\mathrm{D} \_ \text {out }}$ the dialysate flows in the inlet and outlet lines, respectively; $\mathrm{C}_{\mathrm{D} \_ \text {in_Na+ }}$ and $\mathrm{C}_{\mathrm{D} \_ \text {out_Na+ }}$ the dialysate $\mathrm{Na}^{+}$concentrations in the inlet and outlet lines, respectively; and $t_{d}$ the treatment time.

\section{6 | Statistical analyses}

Qualitative variables were expressed as number (percentages). Quantitative variables were expressed as median [min-max].

Regarding the comparative quantification of (a) plasma sodium concentration (ionic dialysance vs. potentiometry), (b) net ionic mass balance (flux vs. inventory models), and (c) blood-side (Ionic Flux) versus dialysate-side approaches, a scatter of differences was visualized according to the Bland-Altman representation. Mean and limits of agreement, defined as mean $\pm 1.96 \mathrm{SD}$ were computed.

In addition, a simple regression analysis and the Spearman's correlation coefficient (rho) were used to determine the relationships (a) between ionic dialysance and potentiometry to measure plasma sodium concentration and (b) between bloodside (Ionic Flux) and dialysate-side approaches.

Friedman test and Wilcoxon matched-pairs signed rank test were used to evaluate the differences between all models (flux vs. inventory).

Wilcoxon matched-pairs signed rank test was used to evaluate (a) differences between pre-dialysis and post-dialysis $\mathrm{Na}+$ concentrations and (b) differences in diffusive and convective parts between modalities.

Values were considered statistically significant at $P<.05$. All analyses were carried out with GraphPad Prism (v 6.01, GraphPad Software, Inc., San Diego, CA, USA).

\section{3 | RESULTS}

\section{1 | Patient characteristics}

Main clinical and biological characteristics of patients at baseline including anthropometric data are summarized in Table 1 . Total body water measured by MF-BIA was 31.4 [26.7-41.1] liters which represents 0.48 [0.41-0.56] \% of dry body weight. Fluid status as assessed by MF-BIA was well controlled in our population. Median fluid overload as measured by MF-BIA was estimated at $1.0[-0.2-1.8]$ liters. Of note, fluid overload calculated during the pre-dialysis period by bioimpedance, refers to the "theorical or target dry weight" that should be aimed in post-dialysis but not necessarily the post-dialysis weight further reached. 
TA B LE 1 Characteristics of the study population at baseline

\begin{tabular}{|c|c|}
\hline Parameters & CKD-5D \\
\hline $\mathrm{N}$ & 10 \\
\hline Male (\%) & $9(90.0 \%)$ \\
\hline Age (years) & $76.3[57.6-84.4]$ \\
\hline \multicolumn{2}{|l|}{ Etiology of ESRD (\%) } \\
\hline Vascular and hypertensive nephropathy & $1(10 \%)$ \\
\hline Glomerulonephritis & $1(10 \%)$ \\
\hline Diabetic nephropathy & $2(20 \%)$ \\
\hline Cystic renal disease & $2(20 \%)$ \\
\hline Unknown cause & $2(20 \%)$ \\
\hline Other cause & $2(20 \%)$ \\
\hline Patients with diabetes mellitus (\%) & $4(40 \%)$ \\
\hline Patients with hypertension (\%) & $7(70 \%)$ \\
\hline Dialysis vintage (years) & $2.3[0.8-13.4]$ \\
\hline Vascular access, AVF (\%) & $8(80.0 \%)$ \\
\hline Anuric patients (\%) & $9(90.0 \%)$ \\
\hline 24-hour urine volume over the 6 last months (L) & $1.5[1.5-1.6]$ \\
\hline Dry body weight (kg) & $70.3[54.0-79.0]$ \\
\hline $\mathrm{V}_{\text {Watson }}(\mathrm{L})$ & $37.3[31.0-42.0]$ \\
\hline $\mathrm{V}_{\text {MF-BIA }}(\mathrm{L})$ & $31.4[26.7-41.1]$ \\
\hline $\mathrm{V}_{\mathrm{OCM}}(\mathrm{L})$ & $35.3[27.8-48.0]$ \\
\hline $\mathrm{SBP}(\mathrm{mm} \mathrm{Hg})$ & $148[88-177]$ \\
\hline $\mathrm{DBP}(\mathrm{mm} \mathrm{Hg})$ & $68[27-79]$ \\
\hline Hemoglobin (g/dL) & $11.4[10.7-12.3]$ \\
\hline Hematocrit (\%) & $35.1[32.8-37.8]$ \\
\hline Albumin $(\mathrm{g} / \mathrm{L})$ & $37.5[32.0-44.0]$ \\
\hline
\end{tabular}

Note: Values were described using proportions for categorical variables and median [min-max] for quantitative variables.

Abbreviations: AVF, arterio venous fistulae; DBP, diastolic blood pressure; ESRD, end stage renal disease; MF-BIA, multi frequency bioimpedance analysis; OCM, online clearance monitoring; SBP, systolic blood pressure; $\mathrm{V}$, volume of total body water.

Treatment prescription and clinical performances of renal replacement therapy are summarized in Table 2. It is notable that plasma sodium concentration was not modified by dialysis session $(P=$ n.s. $)$.

\section{2 | Comparison of plasma sodium concentration $\left[\mathrm{Na}^{+}\right]$was measured by ionic dialysance and potentiometry (laboratory)}

The comparative quantification of plasma sodium concentration $\left[\mathrm{Na}^{+}\right]$measured by ionic dialysance and potentiometry (laboratory) is depicted in the Bland-Altman bias analysis (Figure 1). Limits of agreement with 95\% confidence intervals $(\mathrm{CI})$ were from -4.02 to 2.77 . The deviation of plasma sodium concentration $\left[\mathrm{Na}^{+}\right]$estimated by ionic dialysance versus potentiometry is minimal with no systematic bias. The agreement may be considered as acceptable for clinical purpose. Figure 2 confirms the correlations between both methodologies (Spearman's rho $=0.613 ; P<.0001$ ). In the light of these results and in order to be consistent, all the following calculations were performed using ionic dialysance method for plasma sodium determination.

\section{3 | Comparison of sodium mass transfer models (blood-side approach)}

Net sodium mass transfer results expressed in $\mathrm{mmol} / \mathrm{session}$ by the different methods (Flux vs. Inventory models) are presented in Figure 3. As shown, a slight difference was observed between models with hf-HD (-222.6 [-585.1-61.3], -256.4 [-607.8-43.7], -258.9 [-609.8-41.3], and -258.5 [-607.8-43.5] mmol/session with Flux and Inventory models using $\mathrm{V}_{\text {Watson }}, \mathrm{V}_{\text {MF-BIA }}$, and $\mathrm{V}_{\mathrm{OCM}}$ values for volumes of total body water, respectively), and ol-HDF modalities $(-235.3[-707.4-128.3],-264.9$ [-595.5-50.8], -267.4 [-598.1-44.1], and -266.0 [-595.6-55.6] mmol/session with Flux and Inventory models using $\mathrm{V}_{\text {Watson }}, \mathrm{V}_{\text {MF-BIA }}$, and $\mathrm{V}_{\mathrm{OCM}}$ values for volumes of total body water, respectively).

Bland-Altman analyses of net sodium mass removal comparing Flux and Inventory models are presented in Figure 4. As shown, when considering Flux method as a reference, Inventory models overestimated ionic mass removal by 25.4 , 27.5 , and $26.4 \mathrm{mmol} / \mathrm{session}$ when using $\mathrm{V}_{\text {Watson }}, \mathrm{V}_{\text {MF-BIA, }}$, and $\mathrm{V}_{\mathrm{OCM}}$ values for volumes of total body water, respectively.

\subsection{Comparison of sodium mass transfer models (blood-side vs. dialysate-side approaches)}

The comparative quantification of ionic mass balance using blood-side (Ionic Flux) and dialysate-side approaches is depicted in the Bland-Altman bias analysis (Figure 5). Limits of agreement with $95 \%$ confidence intervals (CI) were from -166.2 to 207.2. The deviation of ionic mass balance estimated by blood-side versus dialysate-side approaches is minimal with no systematic bias. The agreement may be considered as acceptable for clinical purpose. Figure 6 confirms the correlations between both methods (Spearman's rho $=0.806 ; P<.0001$ ).

\section{5 | Sodium mass removal: comparison of hf-HD and ol-HDF}

On a session basis, net sodium mass removal per session $(\mathrm{n}=120)$ calculated by the Flux model was -222.6 $[-585.1-61.3]$ and $-235.3[-707.4-128.3] \mathrm{mmol} / \mathrm{session}$ in 
TAB LE 2 Characteristics of dialysis parameters

\begin{tabular}{|c|c|c|c|}
\hline Parameters & All & hf-HD & ol-HDF \\
\hline Number of sessions & 120 & 60 & 60 \\
\hline \multicolumn{4}{|l|}{ High-flux dialyzers used (\%) } \\
\hline Polysulfone, PS & $8(80.0 \%)$ & $8(80.0 \%)$ & $8(80.0 \%)$ \\
\hline Polyethersulfone, PES & $1(10.0 \%)$ & $1(10.0 \%)$ & $1(10.0 \%)$ \\
\hline Polyester-polymer alloy, PEPA & $1(10.0 \%)$ & $1(10.0 \%)$ & $1(10.0 \%)$ \\
\hline HDF, Post-dilution mode (\%) & - & - & $60(100.0 \%)$ \\
\hline Duration of dialysis session (hour) & $3.89[2.92-5.97]$ & $3.88[2.92-5.97]$ & $3.90[2.92-4.15]$ \\
\hline Dialysate $\left[\mathrm{Na}^{+}\right]$prescription $(\mathrm{mM})$ & $138[138-140]$ & $138[138-140]$ & $138[138-140]$ \\
\hline Intradialytic weight change (pre-post) $(\mathrm{kg})$ & $1.9[-0.2-4.2]$ & $1.8[-0.1-4.2]$ & $2.0[-0.2-4.2]$ \\
\hline Blood flow (mL/min) & $396[302-400]$ & 398 [302-399] & 395 [305-400] \\
\hline Dialysate flow (mL/min) & $500[500-800]$ & $500[500-800]$ & 500 [500-795] \\
\hline Substitution volume (L) & - & - & $19.7[12.6-25.6]$ \\
\hline Substitution flow (mL/min) & - & - & $92.5[55.0-140.0]$ \\
\hline $\mathrm{KUF}(\mathrm{mL} / \mathrm{min})$ & $8.6[0.0-17.1]$ & $8.4[0.0-17.1]$ & $8.8[0.0-16.5]$ \\
\hline Convective flow rate $(\mathrm{mL} / \mathrm{min})$ & $40.5[0.0-140.0]$ & $8.0[0.0-17.0]$ & $101.0[64.0-140.0]$ \\
\hline Convective volume (L/session) & $9.4[0.0-27.7]$ & $1.9[0.0-4.2]$ & $21.5[14.7-27.7]$ \\
\hline Ionic dialysance $\mathrm{K}_{\mathrm{OCM}}(\mathrm{mL} / \mathrm{min})$ & $229.5[154.0-290.0]$ & $225.0[188.0-290.0]$ & $238.0[154.0-276.0]$ \\
\hline Plasma $\left[\mathrm{Na}^{+}\right]_{\text {pre }}(\mathrm{mM})$ & $138.8[132.7-144.0]$ & $138.8[132.7-142.9]$ & $138.9[135.1-144.0]$ \\
\hline Plasma $\left[\mathrm{Na}^{+}\right]_{\text {post }}(\mathrm{mM})$ & $139.7[132.9-143.3]^{\text {n.s. }}$ & $139.4[132.9-143.3]^{\text {n.s. }}$ & $139.9[136.8-143.1]^{\text {n.s. }}$ \\
\hline Urea $(\mathrm{Kt} / \mathrm{V})_{\text {sp_Daugirdas }}$ & $1.77[1.41-2.34]$ & $1.77[1.41-2.19]$ & $1.79[1.51-2.34]$ \\
\hline Urea $(\mathrm{Kt} / \mathrm{V})_{\text {eq_Daugirdas }}$ & $1.45[1.17-1.95]$ & $1.43[1.17-1.83]$ & 1.47 [1.22-1.95] \\
\hline
\end{tabular}

Note: Values were described using proportions for categorical variables and median [min-max] for quantitative variables. ${ }^{\text {n.s. }}$ means no significant post-treatment to pretreatment differences of plasma $\left[\mathrm{Na}^{+}\right]$.

Abbreviations: eq, equilibrated; hf-HD, high-flux hemodialysis; ol-HDF, on line hemodiafiltration; sp, single pool.

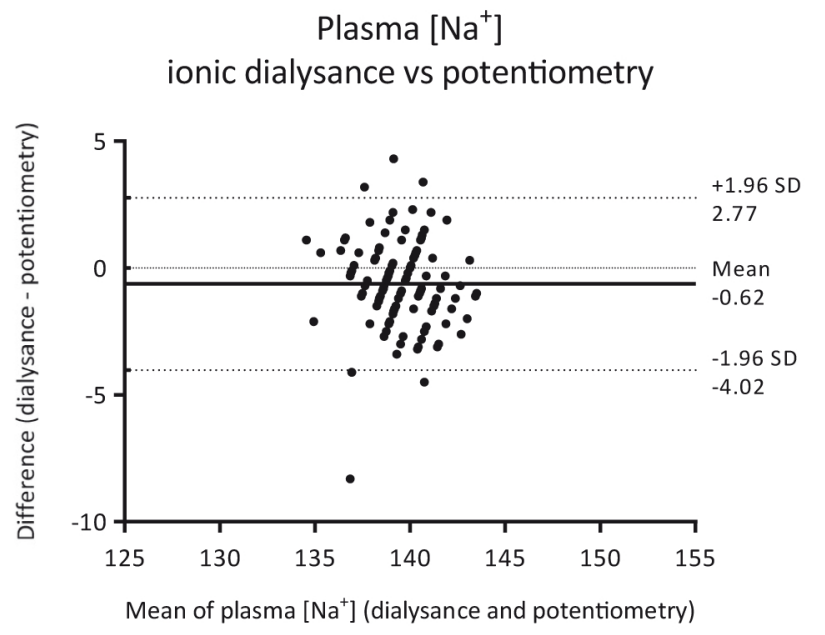

F I G URE 1 Bland-Altman bias plot for plasma $\left[\mathrm{Na}^{+}\right]$measured by ionic dialysance and potentiometry (laboratory). Solid line represents the mean difference and dotted lines represent $95 \%$ limits of agreement. All values are expressed in mM. The median [Q1, Q3] difference between methods was $-0.36[-1.13,0.29] \%$

hf-HD and ol-HDF, respectively, without significant differences between modalities $(P=$ n.s. $)$. Interestingly, net ionic mass balance calculated from each Inventory model did not

\section{Correlation between plasma $\left[\mathrm{Na}^{+}\right]$measured by ionic dialysance and potentiometry}

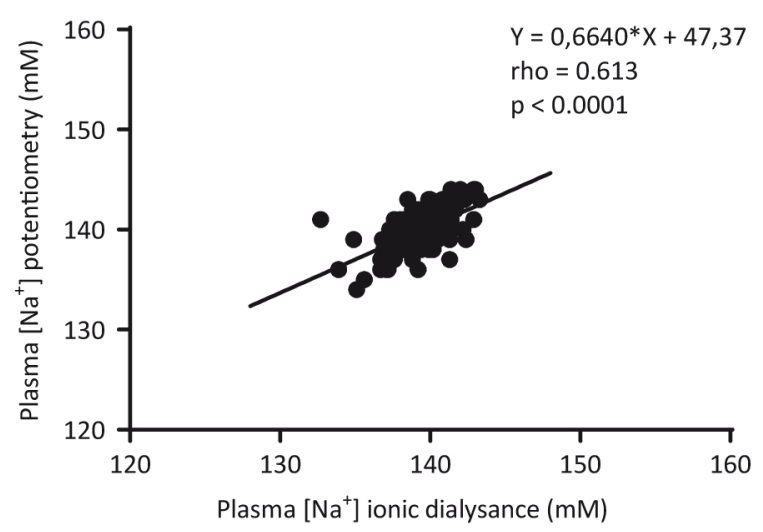

F I GURE 2 Correlation between plasma $\left[\mathrm{Na}^{+}\right]$measured by ionic dialysance and plasma $\left[\mathrm{Na}^{+}\right]$measured by potentiometry (laboratory)

significantly differ between hf-HD and ol-HDF as well, but was significantly different from the Flux model in hf-HD $(P \leq .0042)$ and ol-HDF $(P \leq .0171)$.

On a weekly basis, net sodium mass removal using Flux and Inventory Watson models according to session number 
(A)

Net sodium mass transfer

(blood-side approach)

hf-HD

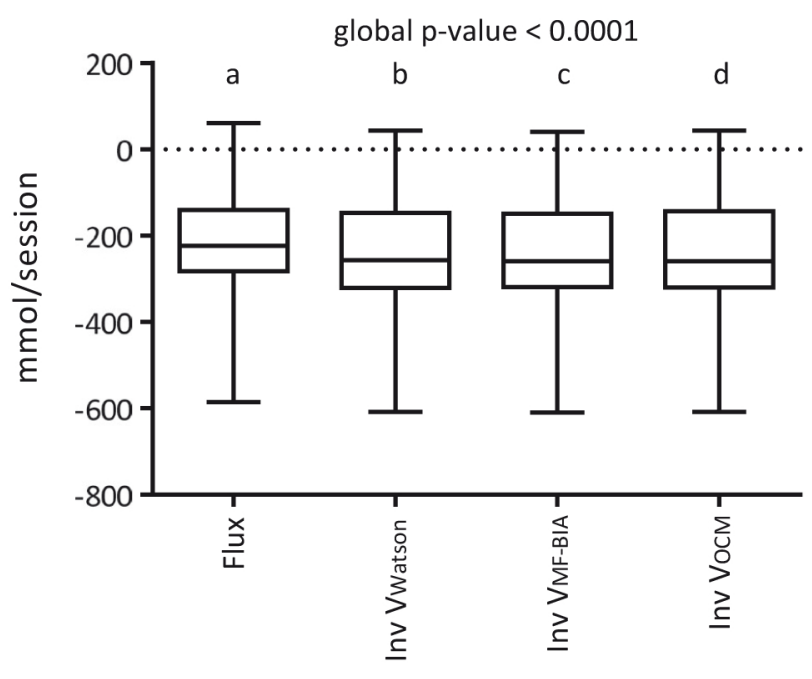

(B)
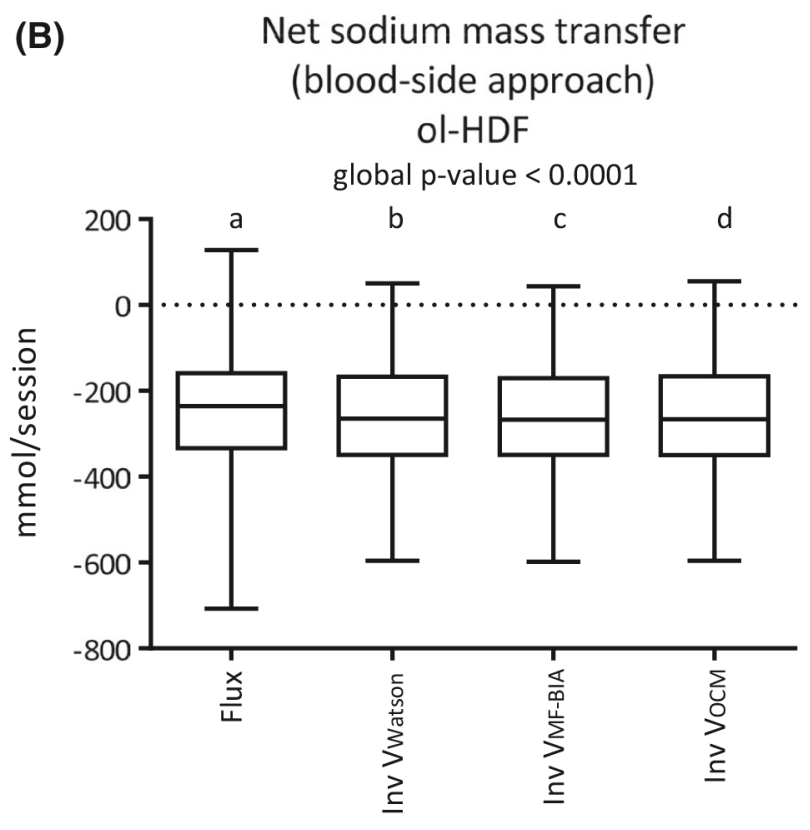

F I G U RE 3 Net sodium mass transfer (blood-side approach) according to the calculation method used. A, hf-HD, B, ol-HDF. hf-HD, high-flux hemodialysis; Inv, inventory model; MFBIA, multifrequency bioimpedance analysis; ol-HDF, on-line hemodiafiltration; OCM, online clearance monitoring. ${ }^{\mathrm{a}-\mathrm{d}}$ Box plots not sharing a common letter are significantly different at $P<.05$ (Wilcoxon matched-pairs signed rank test)

are presented in Figure 7. Interestingly, a significant difference in removal between session \#1 and \#2 was observed in hf-HD modality using Inventory Watson model, with the first session of the week accounting for 37.2 [16.9-51.9] \% of total sodium mass removal for the week while the two other sessions accounted only for $30.1[-16.8-41.1]$ and 28.7
[18.3-99.8] \%, respectively. In the Flux model, a difference between sessions (\#1 and \#3 in this model) was also noted with the hf-HD modality.

This sodium mass discrepancy between sessions is reflecting the impact of the 3 days weekend interval and the higher interdialytic weight gain due to sodium and fluid intake.

Cumulative net ionic mass balance on a weekly basis remained virtually similar in hf-HD and ol-HDF. Cumulative net sodium mass balance using the Flux model was -702.0 $[-1267.0$ to -68.5$]$ versus $-816.7[-1304.0-132.4] \mathrm{mmol}$ $(P=$ n.s. $)$ in hf-HD and ol-HDF, respectively.

Finally, Table 3 represents the diffusive and convective parts of sodium removal using the Flux model. It clearly demonstrates that net $\mathrm{Na}^{+}$mass removal relies on convection which overwhelms a potential diffusive sodium load both in hf-HD and ol-HDF.

\subsection{Net sodium mass removal per patient}

Net sodium mass removal per patient is presented in Figure 8 . As indicated, net sodium mass removal reflects individual patient profile and sodium dietary intake habits. It is interesting to note that one patient (Pat-1) has kept significant residual kidney function and that the patient's sodium intake remained relatively constant over time reflecting patient diet observance and profile.

\section{DISCUSSION}

The present study explored new approaches for assessing sodium mass removal in dialysis patients using tools either embedded on the hemodialysis machine (ie, ionic dialysance sensor) and/or available for estimating more objectively total body water content in dialysis patients (ie, MF-BIA). Combination of these tools permitted us to develop a more accurate approach to assess sodium mass balance in hemodialysis and/or hemodiafiltration patients. This quantitative sodium mass removal assessment is in line with the aim of adjusting and individualizing renal replacement therapy in CKD-5D patients.

Ionic dialysance sensor embedded in hemodialysis machines provides a precise way of quantifying dialysis clinical performances on a regular basis without additional blood sampling and burden either for patient or caregivers. ${ }^{27,28}$ Periodic ionic dialysance relies on a validated process reported by Polaschegg et al that consists of measuring dialysate conductivity at the dialyzer inlet and outlet ports at two different conductivity inlet values (increase and decrease) and calculating instantaneous ionic dialysance from traditional formula integrating blood and dialysate flow. Ionic dialysance $\left(\mathrm{K}_{\mathrm{OCM}}\right)$, reflecting urea and small solute clearance, 
Net sodium mass transfer

Flux vs Inventory $V_{\text {Watson }}$

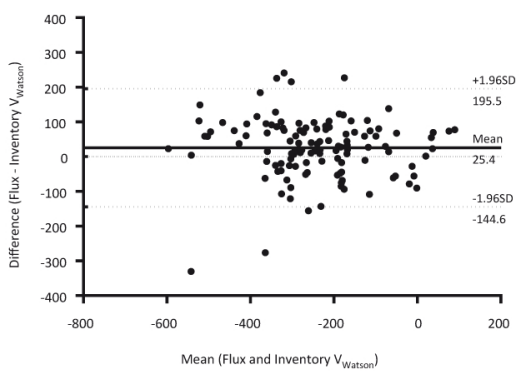

Net sodium mass transfer

Flux vs Inventory $V_{\text {MF-BIA }}$

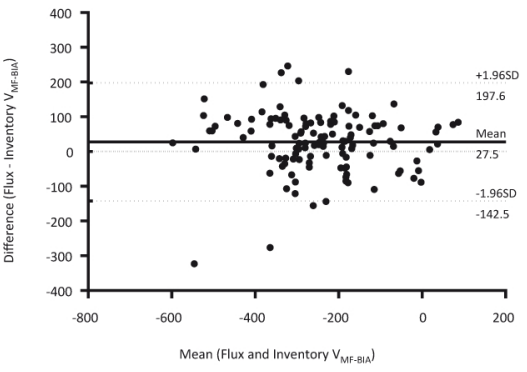

Net sodium mass transfer

Flux vs Inventory $V_{\text {OCM }}$

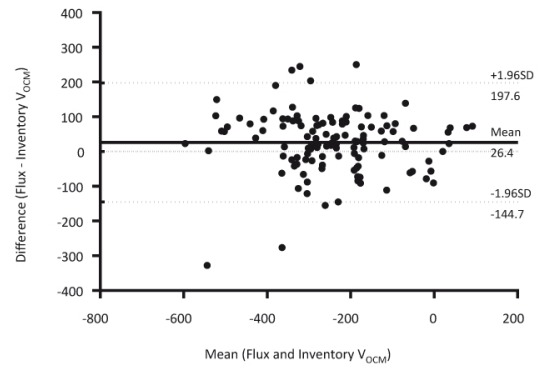

F I G U RE 4 Bland-Altman bias plot for net sodium mass balance (blood-side approach) measured from Flux model and Inventory (A) $V_{\text {Watson }}$ (B) $\mathrm{V}_{\text {MF-BIA }}$, and (C) $\mathrm{V}_{\text {OCM }}$ models. Solid line represents the mean difference and dotted lines represent $95 \%$ limits of agreement. All values are expressed in mmol/session. MF-BIA, multi frequency bioimpedance analysis; OCM, online clearance monitoring; V, volume

Sodium mass transfer using

Blood-side vs Dialysate-side approaches

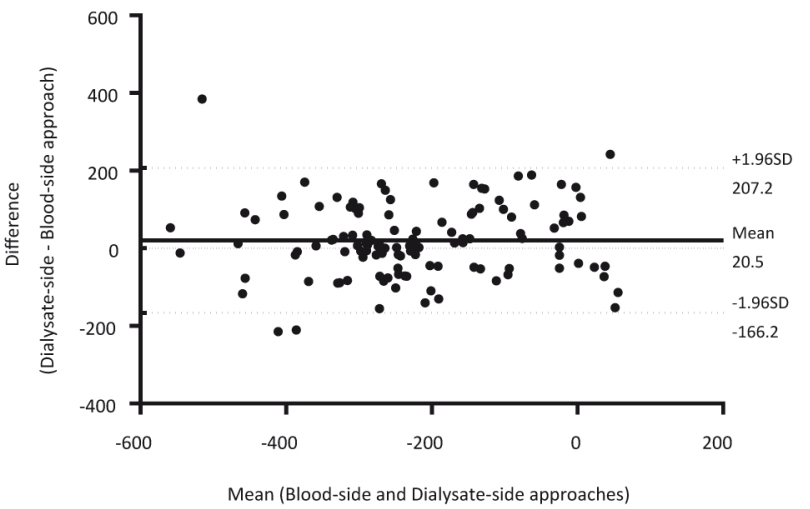

F I G URE 5 Bland-Altman bias plot for blood-side (Ionic Flux) and dialysate-side approaches. Solid line represents the mean difference and dotted lines represent $95 \%$ limits of agreement. All values are expressed in $\mathrm{mmol} / \mathrm{session}$

is ordinarily used to quantify dialysis efficiency from periodic measurements (every 30 minutes) and to provide an integrated dialysis performance $\left(\mathrm{K}_{\mathrm{OCM}}\right)$ throughout the complete dialysis session. ${ }^{28}$ Overall ionic clearance $\left(\mathrm{K}_{\mathrm{OCM}}\right)$ is then used as a surrogate of effective urea clearance both in hemodialysis and ol-HDF expressed either in total clearance over the session ( $\mathrm{K}_{\mathrm{OCM}}$ times treatment time $\left(t_{d}\right)$ in $\mathrm{L} /$ session) or in fractional clearance $\left(\mathrm{K}_{\mathrm{OCM}} t_{d} / \mathrm{V}\right)$ where $\mathrm{V}$ (urea volume or total body water) is referring to an anthropometric value derived from the Watson formula. ${ }^{27,29-31}$

The originality of our work was to develop a simple sodium Flux model relying on $\mathrm{K}_{\mathrm{OCM}}$ values to compute ionic (sodium equivalent) dialysance, and then to estimate the net sodium mass removal using plasma and dialysate sodium concentrations estimated from conductivity measurements. Ionic mass balance has been proposed by different authors to guide dialysate sodium prescription to implement isonatremic dialysis or to prevent sodium patient load. ${ }^{32-37}$ The aim of our study

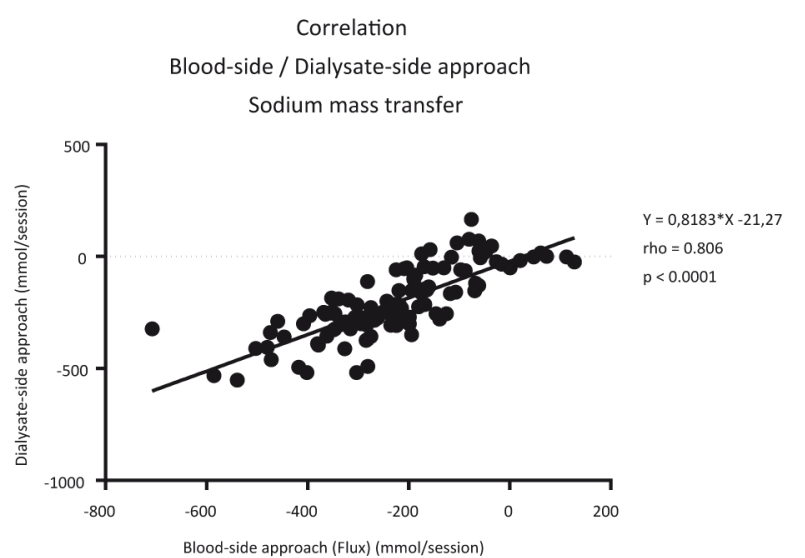

F I G U RE 6 Correlation between blood-side (Ionic Flux) and dialysate-side approaches

was not to modify dialysis prescription or to guide net sodium mass balance but rather to explore the usefulness and validity of this tool in assessing sodium mass removal in standard of care practice in dialysis. In addition, we took advantage of a large and old practice of ol-HDF to explore the impact of this therapeutic option on sodium mass balance. ${ }^{38,39}$ High-volume ol-HDF is currently recommended for improving cardiovascular outcomes in dialysis patients. ${ }^{40}$ However, ol-HDF by reducing net sodium mass removal due to the relative hypotonicity of the ultrafiltrate (ie, Donnan effect and membrane protein polarization effect) versus the isotonic substitution fluid, constitutes a condition that may represent an additional risk of sodium mass imbalance in this already fragile population. ${ }^{14}$ This concern has been highlighted recently by several investigators, a condition that is obviously exacerbated with the use of high substitution volume. ${ }^{12,13}$

In addition, most recent studies exploring sodium mass balance in hemodialysis or hemodiafiltration have used basic Inventory models to assess sodium mass removal. For this purpose, it is proposed to use total body water proxies such as $60 \%$ of body weight or anthropometric estimates either from the Watson ${ }^{25}$ or Chertow $^{41}$ formulae. ${ }^{42-44}$ In our study, we 
Net sodium mass transfer (blood-side approach)

by session and mode

Flux model

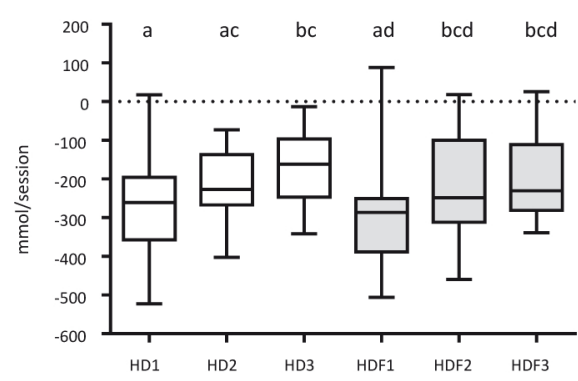

Net sodium mass transfer (blood-side approach)

by session and mode

Inventory $V_{\text {Watson }}$ model

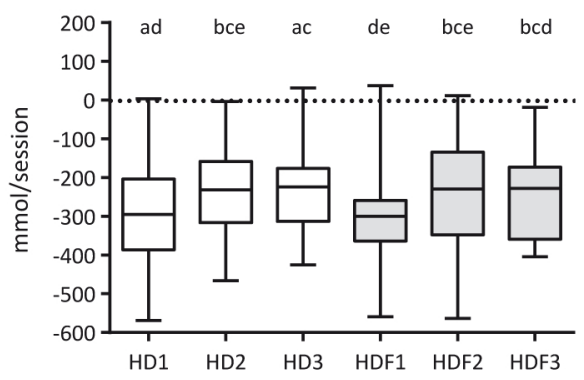

F I G U RE 7 Net sodium mass transfer by session and mode according to (A) Flux and (B) Inventory $V_{\text {Watson }}$ models. HD, hemodialysis; HDF, hemodiafiltration.

${ }^{\mathrm{a}-\mathrm{e}}$ Box plots not sharing a common letter are significantly different at $P<.05$ (Wilcoxon matched-pairs signed rank test

T A B LE 3 Diffusive and convective parts of sodium balance in hf-HD and ol-HDF modalities using Flux model

\begin{tabular}{|c|c|c|c|c|c|c|}
\hline \multirow[b]{2}{*}{ (mmol/session) } & \multicolumn{3}{|l|}{ hf-HD } & \multicolumn{3}{|l|}{ ol-HDF } \\
\hline & Diffusion & Convection & Total & Diffusion & Convection & Total \\
\hline Minimum & -295.5 & -584.4 & -585.1 & -296.9 & -541.7 & -707.4 \\
\hline $25 \%$ Percentile & -10.9 & -331.6 & -282 & -23.95 & -341.9 & -333.9 \\
\hline Median & 52.7 & -268.4 & -222.6 & 39.1 & -281.8 & -235.3 \\
\hline $75 \%$ Percentile & 88.23 & -177.2 & -140.6 & 75.6 & -158.3 & -159.1 \\
\hline Maximum & 150.2 & 0 & 61.3 & 158.1 & 0 & 128.3 \\
\hline
\end{tabular}

Note: $P=\mathrm{n} . \mathrm{s}$. for both diffusion and convection parts between hf-HD and ol-HDF.

Abbreviations: hf-HD, high-flux hemodialysis; ol-HDF, on-line hemodiafiltration.

have used a validated multifrequency bioimpedance spectroscopy device (Body Composition Monitor) to assess true total body water and relative fluid overload in dialysis patients from which we estimated extracellular fluid volume as one third of the total body water. ${ }^{45-47}$ Body composition was measured in all patients before the dialysis session and weight lost during dialysis (fluid removed) was deduced from predialysis total body water content to obtain patient's isovolemic total body water status. ${ }^{48,49}$ Various approaches were used to calculate total body water in our dialysis population including the Watson formula but also a Kt/V-based formula derived from urea kinetic and ionic dialysance. As shown in Table 1, all formulas tend to overestimate significantly total body water by factor of several liters and support the notion that both anthropometric- and kinetic-based approaches may introduce a significant error in sodium mass removal with Inventory approaches. This finding is in line with previous studies investigating this concern. ${ }^{26,44,50}$ Such discrepancy may help to explain differences in net sodium mass balance in regard of calculation method used. Sodium Flux method developed in our study indicated around $17 \%$ lower sodium mass removal in hemodialysis and $7 \%$ lower in hemodiafiltration compared to Inventory methods. It is interesting to note that in Inventory models, net sodium mass balance relies essentially on dialysate plasma sodium concentration changes and clearly less on sodium distribution volume.

An additional point of interest of our findings is the fact that sodium mass removal in high-volume ol-HDF is almost similar to that one achieved in hf-HD. This is in agreement with recent studies addressing this concern. ${ }^{16,17}$ As shown in our study, net sodium mass balance is virtually similar in both dialysis modalities ( -222.6 vs. $-235.3 \mathrm{mmol} / \mathrm{ses}-$ sion using the Flux model) on a dialysis session basis but also on a weekly cumulative basis. Interestingly, the Flux model clearly shows that sodium mass removal is mainly obtained by convection in hf-HD and ol-HDF. The similar efficiency of both dialysis modalities in sodium removal is of high clinical relevance for two reasons: first, because it precludes long-term risk of sodium accumulation exposure and their additional cardiovascular and metabolic-associated risks with ol-HDF; second, it rules out also the notion that better hemodynamic stability reported in ol-HDF is due to substitution fluid by a relatively higher hypertonic solution with a reduced net sodium mass balance. It must be highlighted that these results were obtained in a specific clinical condition fitting with currently recommended volume of exchange in ol-HDF and a dialysate sodium concentration $\left(\mathrm{C}_{\mathrm{D} \_\mathrm{Na}+}=138 \mathrm{mmol} / \mathrm{L}\right)$ lower than mean pre-dialysis patient plasma concentration $\left(\mathrm{C}_{\mathrm{B}_{-} \mathrm{Na}+}=139 \mathrm{mmol} / \mathrm{L}\right)$ mimicking an isonatremic dialysis condition. Indeed, a lower dialysate sodium concentration is required for isonatremic dialysis to comply with diffusive sodium from plasma water concentration that should account for total protein concentration, hematocrit void volume, and the Gibbs-Donnan effect. The difference observed here between $\mathrm{C}_{\mathrm{B} \_ \text {Nat_post }}$ (median value at $139.7 \mathrm{mmol} / \mathrm{L}$ ) and dialysate sodium prescription (median 
Net IMB (blood-side approach) per patient Flux model (All sessions)

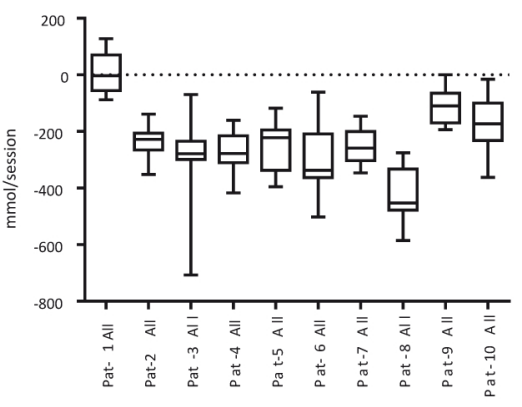

Net IMB (blood-side approach) per patient Flux model (hf-HD)

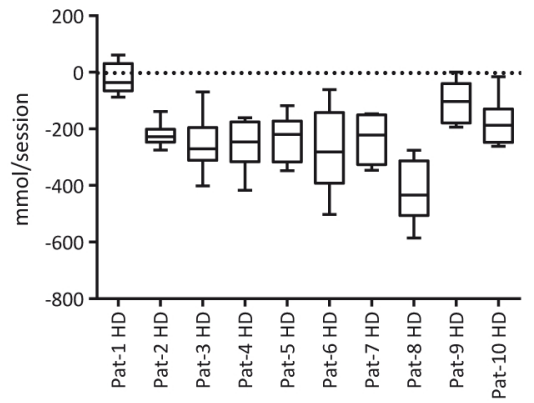

Net IMB (blood-side approach) per patient Flux model (ol-HDF)

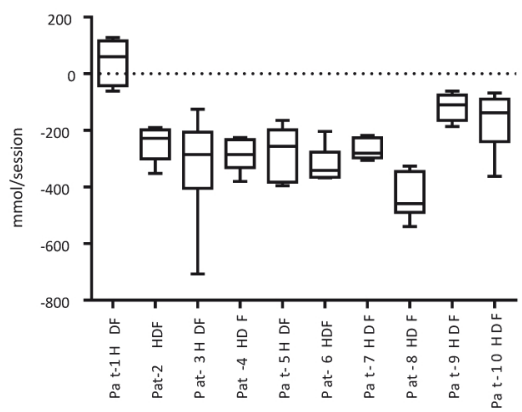

F I G U RE 8 Net ionic mass balance per patient according to Flux model. hf-HD, high-flux hemodialysis; IMB, ionic mass balance; ol-HDF, on-line hemodiafiltration

value at $138 \mathrm{mmol} / \mathrm{L}$ ) could not be interpreted as a positive mass balance. Indeed, plasma sodium concentration was obtained using indirect potentiometry accounting for protein and hematocrit concentrations. In contrast, dialysate sodium concentration was not directly measured but estimated using conductivity which also takes into account other ions. As previously demonstrated by Gaillard et al, ${ }^{32}$ natremia measured at laboratory and natremia estimated using conductivity are not to be confused. In that context, a recent meta-analysis comparing dialysate sodium concentrations based on laboratory dosing reported reassuring data on measured and prescribed dialysate sodium. ${ }^{51}$ Now, it is easy to calculate that, by increasing the volume of substitution, such condition would not be achieved and, therefore, to keep adequate net sodium mass balance, the dialysate sodium concentration should be decreased by $2-3 \mathrm{mmol} / \mathrm{L}$ and then, aligned to patient plasma sodium concentration estimated by the dialysis monitor.

Interestingly, by continuously sensing dialyzer sodium flux in and out on one side and by calculating plasma sodium concentrations on the other side, the new generation of hemodialysis machine will be able to incorporate such a new sodium balancing tool. ${ }^{20-22}$ Prospective studies relying on this tool have recently shown that isonatremic dialysis was easily achieved on a regular basis with high accuracy relying on a totally automated mode driven by dialysis machine and adapted algorithm. Interestingly, results obtained with olHDF did not differ from the hemodialysis ones, meaning that automated sodium balancing modules work with the same accuracy in both modes and whatever the sodium fluxes are. This finding may be easily explained by the fact that sodium balancing module relies on conductivity cells interposed at the dialyzer inlet and outlet ports ensuring a perfect ionic mass balance within the hemodialyzer. ${ }^{29}$

Our study has limitations that may be summarized as follows: first, number of patients and sessions analyzed is limited and as such may not reflect the usual dialysis population. However, automation and reproducibility of measurements provided by the dialysis machine and calculations performed tend to minimize these errors. In addition, net sodium mass removal computed in this cohort is in the range of recent studies and fits with clinical assessment; second, plasma water potassium mass, which can influence plasma water sodium concentration according to the Edelman equation $\left(\left[\mathrm{Na}^{+}\right]=\left(\mathrm{Na}^{+}\right.\right.$plus $\left.\mathrm{K}^{+}\right) /$Total body water $),{ }^{52}$ was measured and then, not accounted for in this study. Moreover, effects caused by glucose, especially when dealing with diabetic patients, may indirectly influence sodium mass balance by increasing plasma tonicity then refilling vascular capacity and subsequently ultrafiltration capacity. In our study, bedside glycemia check was performed as usual care at the start and the end of dialysis sessions with autolet glucose sensoring device. Glycemia remained in all cases in the range of $6-11 \mathrm{mmol} / \mathrm{L}$ meaning that the potential influence on sodium or ionic mass balance calculation was minimal. In addition, glucoseenriched dialysate was used as a standard of care in our unit to prevent losing glucose and to improve dialysis tolerance; third, no clinical outcome was analyzed in parallel to this sodium mass balance study. However, considering fluid status of our dialysis patients as indicated by regular MF-BIA measurement and blood pressure values, there is no signal indicating that our patients were exposed to fluid overload or presenting with uncontrolled blood pressure.

Future interesting clinical perspectives are open with these new tools permitting us to assess sodium mass removal in dialysis patients. Monitoring sodium and fluid management in a dialysis quality assurance program will be facilitated. Assessing sodium mass removal at each dialysis session either on a manual or an automated mode will be of tremendous support for regular clinical support of dialysis patients. If one considers that on a weekly basis, sodium mass removal is equivalent to dietary intake, this precise information gathered regularly and automatically will help caregivers and dietitians to provide personalized diet guidance or to detect early clinical disorders in dialysis patients. Sodium mass balance measurement will also be helpful in assessing 
fluid volume and hemodynamic status of dialysis patients to improve cardiovascular outcomes. It remains to be shown that these sodium tools will be helpful to improve long-term clinical outcomes of dialysis patients. Further outcome-based studies are required in that perspective.

\section{CONCLUSION}

Our study proposes a new approach to calculate sodium mass removal in hemodialysis patients using the ionic dialysance sensor embedded in hemodialysis machines. Our findings support the notion that such a manual approach is easy and accurate enough in the clinical setting to evaluate sodium mass balance and to prevent long-term sodium mass imbalance. In the future, the use of an automated sodium balancing module embedded in the hemodialysis machine could be a practical approach to bridge the gap with fully automated sodium balancing devices.

\section{CONFLICT OF INTEREST}

$\mathrm{BC}$ is a part time employee of FMC acting as senior scientist. AR, MM, ASB, LC, HLM, JPC has no conflict of interest.

\section{REFERENCES}

1. Bie P. Mechanisms of sodium balance: total body sodium, surrogate variables, and renal sodium excretion. Am J Physiol Regul Integr Comp Physiol. 2018;315:R945-62.

2. Dekker MJE, Kooman JP. Fluid status assessment in hemodialysis patients and the association with outcome: review of recent literature. Curr Opin Nephrol Hypertens. 2018;27:188-93.

3. Flythe JE, Brookhart MA. Fluid management: the challenge of defining standards of care. Clin J Am Soc Nephrol. 2014;9:2033-5.

4. Canaud B, Kooman J, Selby NM, Taal M, Francis S, Kopperschmidt $\mathrm{P}$, et al. Sodium and water handling during hemodialysis: new pathophysiologic insights and management approaches for improving outcomes in end-stage kidney disease. Kidney Int. 2019;95:296-309.

5. Canaud B, Chazot C, Koomans J, Collins A. Fluid and hemodynamic management in hemodialysis patients: challenges and opportunities. J Bras Nefrol. 2019;41:550-9.

6. Canaud B, Lertdumrongluk P. Probing "dry weight" in haemodialysis patients: "back to the future". Nephrol Dial Transplant. 2012;27:2140-3.

7. Munoz Mendoza J, Sun S, Chertow GM, Moran J, Doss S, Schiller B. Dialysate sodium and sodium gradient in maintenance hemodialysis: a neglected sodium restriction approach? Nephrol Dial Transplant. 2011;26:1281-7.

8. Penne EL, Sergeyeva O. Sodium gradient: a tool to individualize dialysate sodium prescription in chronic hemodialysis patients? Blood Purif. 2011;31:86-91.

9. Hecking M, Kainz A, Horl WH, Herkner H, Sunder-Plassmann G. Sodium setpoint and sodium gradient: influence on plasma sodium change and weight gain. Am J Nephrol. 2011;33:39-48.
10. Hecking M, Moissl U, Genser B, Rayner H, Dasgupta I, Stuard S, et al. Greater fluid overload and lower interdialytic weight gain are independently associated with mortality in a large international hemodialysis population. Nephrol Dial Transplant. 2018;33:1832-42.

11. Trinh $\mathrm{E}$, Weber $\mathrm{C}$. The dialysis sodium gradient: a modifiable risk factor for fluid overload. Nephron Extra. 2017;7:10-7.

12. Canaud B, Busink E, Apel C, Bowry SK. Is there not sufficient evidence to show that haemodiafiltration is superior to conventional haemodialysis in treating end-stage kidney disease patients? Blood Purif. 2018;46:7-11.

13. Kawanishi $\mathrm{H}$. Is there enough evidence to prove that hemodiafiltration is superior? Blood Purif. 2018;46:3-6.

14. Gotch FA, Sargent JA. Hemofiltration: an unnecessarily complex method to achieve hypotonic sodium removal and controlled ultrafiltration. Blood Purif. 1983;1:9-15.

15. Kimura G, Gotch FA. Serum sodium concentration and body fluid distribution during interdialysis: importance of sodium to fluid intake ratio in hemodialysis patients. Int $\mathbf{J}$ Artif Organs. 1984;7:331-6.

16. La Milia V, Ravasi C, Carfagna F, Alberghini E, Baragetti I, Buzzi $\mathrm{L}$, et al. Sodium removal and plasma tonicity balance are not different in hemodialysis and hemodiafiltration using high-flux membranes. J Nephrol. 2019;32:461-9.

17. Chazot C, Deleuze S, Fadel B, Hebibi H, Jean G, Levannier M, et al. Is high-volume post-dilution haemodiafiltration associated with risk of fluid volume imbalance? A national multicentre crosssectional cohort study. Nephrol Dial Transplant. 2019;34:2089-95.

18. Locatelli F, Di Filippo S, Manzoni C. Relevance of the conductivity kinetic model in the control of sodium pool. Kidney Int Suppl. 2000;76:S89-95.

19. Bosetto A, Bene B, Petitclerc T. Sodium management in dialysis by conductivity. Adv Ren Replace Ther. 1999;6:243-54.

20. Kuhlmann U, Maierhofer A, Canaud B, Hoyer J, Gross M. Zero diffusive sodium balance in hemodialysis provided by an algorithmbased electrolyte balancing controller: a proof of principle clinical study. Artif Organs. 2019;43:150-8.

21. Ságová M, Wojke R, Maierhofer A, Gross M, Canaud B, Gauly A. Automated individualization of dialysate sodium concentration reduces intradialytic plasma sodium changes in hemodialysis. Artif Organs. 2019;43:1002-14.

22. Ponce P, Pinto B, Wojke R, Maierhofer AP, Gauly A. Evaluation of intradialytic sodium shifts during sodium controlled hemodialysis. Int J Artif Organs. 2020;43:620-4.

23. Daugirdas JT. Second generation logarithmic estimates of singlepool variable volume Kt/V: an analysis of error. J Am Soc Nephrol. 1993;4:1205-14.

24. Daugirdas JT, Schneditz D. Overestimation of hemodialysis dose depends on dialysis efficiency by regional blood flow but not by conventional two pool urea kinetic analysis. ASAIO J. 1995;41:M719-24.

25. Watson PE, Watson ID, Batt RD. Total body water volumes for adult males and females estimated from simple anthropometric measurements. Am J Clin Nutr. 1980;33:27-39.

26. Wuepper A, Tattersall J, Kraemer M, Wilkie M, Edwards L. Determination of urea distribution volume for $\mathrm{Kt} / \mathrm{V}$ assessed by conductivity monitoring. Kidney Int. 2003;64:2262-71.

27. Kuhlmann U, Goldau R, Samadi N, Graf T, Gross M, Orlandini G, et al. Accuracy and safety of online clearance monitoring based on conductivity variation. Nephrol Dial Transplant. 2001;16:1053-8.

28. Polaschegg HD. Automatic, noninvasive intradialytic clearance measurement. Int J Artif Organs. 1993;16:185-91. 
29. Gross M, Maierhofer A, Tetta C, Senecal L, Canaud B. Online clearance measurement in high-efficiency hemodiafiltration. Kidney Int. 2007;72:1550-3.

30. Mercadal L, Ridel C, Petitclerc T. Ionic dialysance: principle and review of its clinical relevance for quantification of hemodialysis efficiency. Hemodial Int. 2005;9:111-9.

31. Zaloszyc A, Fischbach M, Schaefer B, Uhlmann L, Salomon R, Krid $\mathrm{S}$, et al. Body composition monitoring-derived urea distribution volume in children on chronic hemodialysis. Pediatr Nephrol. 2016;31:991-9.

32. Gaillard F, Laplanche S, Petitclerc T. Natremia, tonicity, and conductivity measurements in hemodialyzed patients. Int J Artif Organs. 2015;38:288-90.

33. Gaillard F, Petitclerc T. From isonatric to isotonic hemodialysis. Blood Purif. 2018;46:77-80.

34. Mercadal L, Servais A, Venditto M, Renault N, Isnard-Bagnis C, Deray G, et al. Measuring plasma conductivity to detect sodium load in hemodialysis patients. Clin J Am Soc Nephrol. 2008;3:743-6.

35. Locatelli F, Buoncristiani U, Canaud B, Kohler H, Petitclerc T, Zucchelli P. Haemodialysis with on-line monitoring equipment: tools or toys? Nephrol Dial Transplant. 2005;20:22-33.

36. Locatelli F, Manzoni C, Di Filippo S. Electrolyte balancing: modern techniques and outcome. Blood Purif. 2001;19:195-9.

37. Locatelli F, Stefoni S, Petitclerc T, Coli L, Di Filippo S, Andrulli S, et al. Effect of a plasma sodium biofeedback system applied to HFR on the intradialytic cardiovascular stability. results from a randomized controlled study. Nephrol Dial Transplant. 2012;27:3935-42.

38. Canaud B, Koehler K, Bowry S, Stuard S. What is the optimal target convective volume in on-line hemodiafiltration therapy? Contrib Nephrol. 2017;189:9-16.

39. Morena M, Jaussent A, Chalabi L, Leray-Moragues H, Chenine L, Debure A, et al. Treatment tolerance and patient-reported outcomes favor online hemodiafiltration compared to high-flux hemodialysis in the elderly. Kidney Int. 2017;91:1495-509.

40. Canaud B, Vienken J, Ash S, Ward RA, Kidney Health Initiative HDF Workgroup. Hemodiafiltration to address unmet medical needs ESKD patients. Clin J Am Soc Nephrol. 2018;13:1435-43.

41. Chertow GM, Lazarus JM, Lew NL, Ma L, Lowrie EG. Development of a population-specific regression equation to estimate total body water in hemodialysis patients. Kidney Int. 1997;51:1578-82.

42. Koomans HA, Roos JC, Dorhout Mees EJ, Delawi IM. Sodium balance in renal failure. A comparison of patients with normal subjects under extremes of sodium intake. Hypertension. 1985;7:714-21.

43. Lambie SH, Taal MW, Fluck RJ, McIntyre CW. Online conductivity monitoring: validation and usefulness in a clinical trial of reduced dialysate conductivity. ASAIO J. 2005;51:70-6.
44. Lindley EJ, Chamney PW, Wuepper A, Ingles H, Tattersall JE, Will EJ. A comparison of methods for determining urea distribution volume for routine use in on-line monitoring of haemodialysis adequacy. Nephrol Dial Transplant. 2009;24:211-6.

45. Broers NJH, Canaud B, Dekker MJE, Sande FM, Stuard S, Wabel $\mathrm{P}$, et al. Three compartment bioimpedance spectroscopy in the nutritional assessment and the outcome of patients with advanced or end stage kidney disease: what have we learned so far. Hemodial Int. 2020;24:148-61.

46. van der Sande FM, van de Wal-Visscher ER, Stuard S, Moissl U, Kooman JP. Using bioimpedance spectroscopy to assess volume status in dialysis patients. Blood Purif. 2020;49:178-84.

47. Wabel P, Chamney P, Moissl U, Jirka T. Importance of whole-body bioimpedance spectroscopy for the management of fluid balance. Blood Purif. 2009;27:75-80.

48. Moiss1 U, Arias-Guillén M, Wabel P, Fontseré N, Carrera M, Campistol JM, et al. Bioimpedance-guided fluid management in hemodialysis patients. Clin J Am Soc Nephrol. 2013;8:1575-82.

49. Velasco N, Chamney P, Wabel P, Moissl U, Imtiaz T, Spalding E, et al. Optimal fluid control can normalize cardiovascular risk markers and limit left ventricular hypertrophy in thrice weekly dialysis patients. Hemodial Int. 2012;16:465-72.

50. Daugirdas JT, Greene T, Depner TA, Chumlea C, Rocco MJ, Chertow GM. Anthropometrically estimated total body water volumes are larger than modeled urea volume in chronic hemodialysis patients: effects of age, race, and gender. Kidney Int. 2003;64:1108-19.

51. Ng JK, Smyth B, Marshall MR, Kang A, Pinter J, Bassi A, et al. Relationship between measured and prescribed dialysate sodium in haemodialysis: a systematic review and meta-analysis. Nephrol Dial Transplant. 2020. Epub ahead of print. https://doi.org/10.1093/ ndt/gfaa287

52. Edelman IS, Leibman J, O'Meara MP, Birkenfeld LW. Interrelations between serum sodium concentration, serum osmolarity and total exchangeable sodium, total exchangeable potassium and total body water. J Clin Invest. 1958;37:1236-56. 